\title{
Supernumerary chromosome variation and heterochromatin distribution in the endemic New Zealand frog Leiopelma hochstetteri
}

\author{
David M. Green ${ }^{1}$, James Kezer ${ }^{2}$, and Ronald A. Nussbaum ${ }^{3}$ \\ 1 Redpath Museum. McGill University, Montrcal, PQ, 113A 2K6 Canada \\ 2 Department of Biology. University of Oregon, Fugene, OR 97403 USA \\ ${ }^{3}$ Muscum of 7.oology. University of Michigan. Ann Arbor. MI 48109 USA
}

\begin{abstract}
Specimens of the endemic New Zealand frog Leiopelma hochstetteri from Tapu on North Island were found to have six, nine or ten supernumerary chromosomes in their karyotypes. In comparison with previously published dati, these results further indicate probable gengraphic variation in supernumerary chromosome number between populations. Increased numbers of supcrnumeraries in these frogs is correlated with apparent decrease of centromeric heterochromatin in the five large metacentric chromosomes of the karyotype, as detected by (-banding. Meiosis was abnormal in a malc with a high number of supernumeraries. In lampbrush preparations from a single female with one supernumerary univalent, the supernumerary often had a denser. beaded appearance in comparison with the regular bivalents. Evidence is consistent with the notion that these supernumerary chromosomes may have arisen from centromeric fragments.
\end{abstract}

\section{Introduction}

The three species comprising the endemic New Zealand genus leiopelma are of ten considered to be among the most primitive of living frogs (Bell 1982: Ducllman and Trueb 1986). The most widespread of thesc species. L. hochstetteri. is found in damp seepages and stream banks in scattered localities on the North Island of Now Lealand (Fig. 1). L. hamiltoni and $L$. archey $i$ are extremely restricted in range. The three species are considered to be threatened in New 7.ealand (Bell 1986), especially L, hamilloni. While L. hamiltomi and $L$. archey $i$ have both been shown to have $2 n=$ 18 chromosomes. $L$. hochstetteri has $2 n=22$ chromosomes plus varying numbers of very small supernumerary, or Bchromosomes (Morescalchi 1967; Stephenson cl al. 1972, 1974: Green et al. 1984a). The regular karyotype, or A-set of chromosomes, of $I$. hochstetteri consists of five pairs of large metacentric chromosomes and six pairs of smaller telocentric chromosomes, one of which has a prominent secondary constriction.

Supernumerary chromosomes. always considered to be unusual in animals, are rare in anurans; only four specics other than $L$. hochstetteri are reported in the literature to possess them (Jones and Rees 1982) although there exist additional, unpublished cxamples (J.P. Bogart, personal communication). The origin of supernumerary chromosomes in animal karyotypes has not been convincingly explained (Iones and Rees 1982). Considering the highly het-

Offprint requests 10 : D.M. Grocn erochromatic nature of supernumerary chromosomes in many specics. it is possible that they may have arisen, in some cases, as free centromeres or centromeric fragments (see Jones and Rees 1982), but there is little corroborating evidence. Supernumerary chromosomes have been associated, in various instances, with particular kinds of meiotic chromosome behaviour, decreased developmental ralc, reduced fitness or viability and ior increased C-values (Harvey and I Icwill 1979; Jones and Rees 1982).

Larlier, we reported on the supernumerary chromosomes and heterochromatin of specimens of $L$. hochstetteri obtained from Dome Vallcy, near Warkworth north of Auckland, New 7caland (Fig. 1), including comments on a triploid female (Green et al. 1984a). The number of supernumerary chromosomes per individual in that sample was low. All females except the triploid had one supernumerary while the males had none. The triploid had two supernumeraries. The supernumerarics were not unusually heterochromatic; C-bands were confined to the centromeres, as is usual among the regular set of chromosomes. All other chromosomes were similarly C-band positive at the centromeres with an additional C-band observed in association with the prominent secondary constriction on chromosome 7. Stephenson et al. (1972) presented karyotype data from frogs taken from Tokatea Ridge on the Coromandel Peninsula of the North Island of New Zealand (Fig. 1). These specimens. all males, had either two or four supernumeraries. Another male from Dome Valley was without supernumeraries. Two females from Dome Vallcy were examined by Morescalchi (1967). They had 1 and 12 supernumeraries, respectively.

We are now able to present karyotypic data, including C-banding information on heterochromatin distribution, from additional specimens of $L$. hochstetteri from a third locality, Tapu. on the Coromandel Range (Fig. 1). In addition, we present further information from two more specimens of this rare frog from Dome Valley, including data from lampbrush ehromosomes obtained from the oöcytes of a Dome Vallcy femalc. This information gives additional insight into variation in heterochromatin distribution and supernumerary chromosome numbers within the karyotype of this species.

\section{Materials and methods}

Four frogs collected on the west side of the Tapu-Coroglen Saddle of the Coromandel Range on the North Island of New Zcaland by Dr. Joan Robb in September, 1983 were 


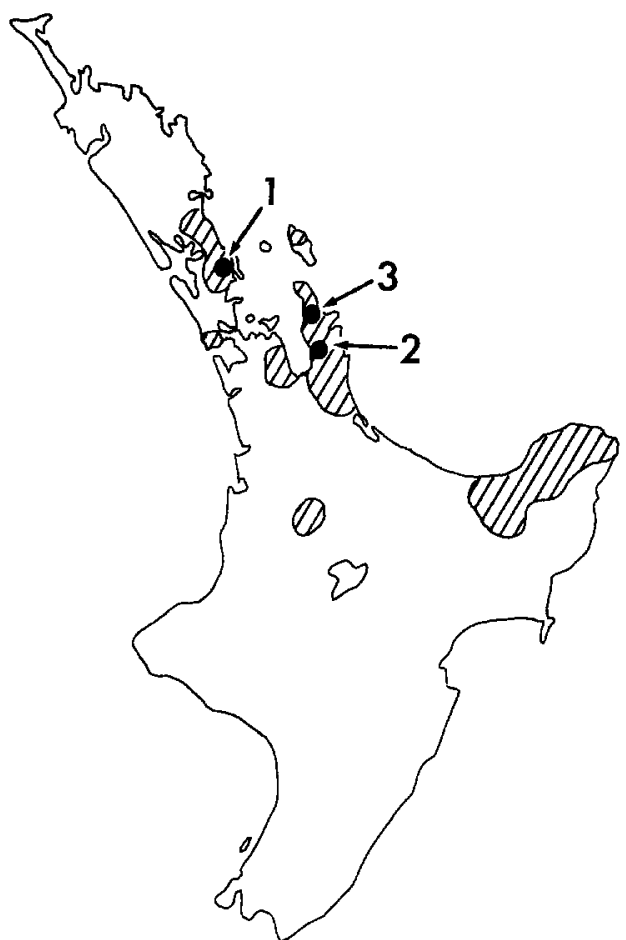

Fig. 1. Map of North Island of New 7.ealand showing the range of Leiopelma hochstetteri (cross-hatching) and localitics mentioned in the text where chromosome information has been obtained. 1 Dome Valley, Warkworth: 2 Tapu: 3 Tokatca Ridge

examined. Chromosomes from one male and onc female, deposited at the California Academy of Sciences (CAS Nos. 156252-3), were obtained using Bogart's (1981) corneal epithelium squash method while chromosomes from two males, deposited at the Museum of Zoology, University of Michigan (UMMZ Nos. 180360-1) were obtained with Keyer and Sessions' (1979) gut epithelium and testis squash methods. Lampbrush chromosome preparations, using methods described by Kezer el al. (1960), were made from the oöcytes of two females from Dome Valley, Warkworth,
New Zealand collected in March, 1976, by Joan Robb (UMMZ Nos. 146848 and 146850).

At least 20 metaphase chromosome spreads per specimen were examined under phase contrast optics. Photomicrographs of good sprcads were numerically analyzed with the CHROMPAC III computer-assisted analysis system (Green et al. 1984b). The nomenclature used for chromosomes is that suggested by Levan et al. (1964) and modified by Green el al. (1980). Schmid's (1978) C-banding method was used to demonstrate the presence of the heterochromatic regions.

\section{Results}

When examined unstained with phase contrast (Fig. $2 \mathrm{a}, \mathrm{b}$ ), the 11 pairs of chromosomes of the A-set of the Tapu specimens did not differ in any marked way from results obtained in previous studies of the karyotype of $L$. hochstetteri. Neither were significant differences found upon medsurement and numerical analysis of the A-chromosomes when compared with published data (Green et al. 1984a). All Tapu specimens had five pairs of large metacentric chromosomes and six pairs of smaller telocentric chromosomes, one of which, previously identified as the seventh chromosome (Green et al. 1984a), had a conspicuous median secondary constriction. Some of the telocentric chromosomes possessed very small, but definable, short arms. However. the Tapu specimens had different numbers of supernumerary chromosomes present than had previously been observed in $L$. hochstetteri (Table 1). One malc and one female each had six supernumerary chromosomes, one male had nine supernumerary chromosomes and one male had ten supernumerary chromosomes. All supernumerary chromosomes observed were strictly telocentric with one exception: one of the supernumerary chromosomes of the male with ten was metacentric (Fig. 2a).

The supernumerary chromosomes seen in L. hochstetteri from Tapu were not all equal in size. If the combined length of the $\Lambda$-chromosomes is set to equal $100 \%$, the largest supernumerarics observed were about $1.4 \%$ of the length of the $A$-set while the smallest supernumeraries were about

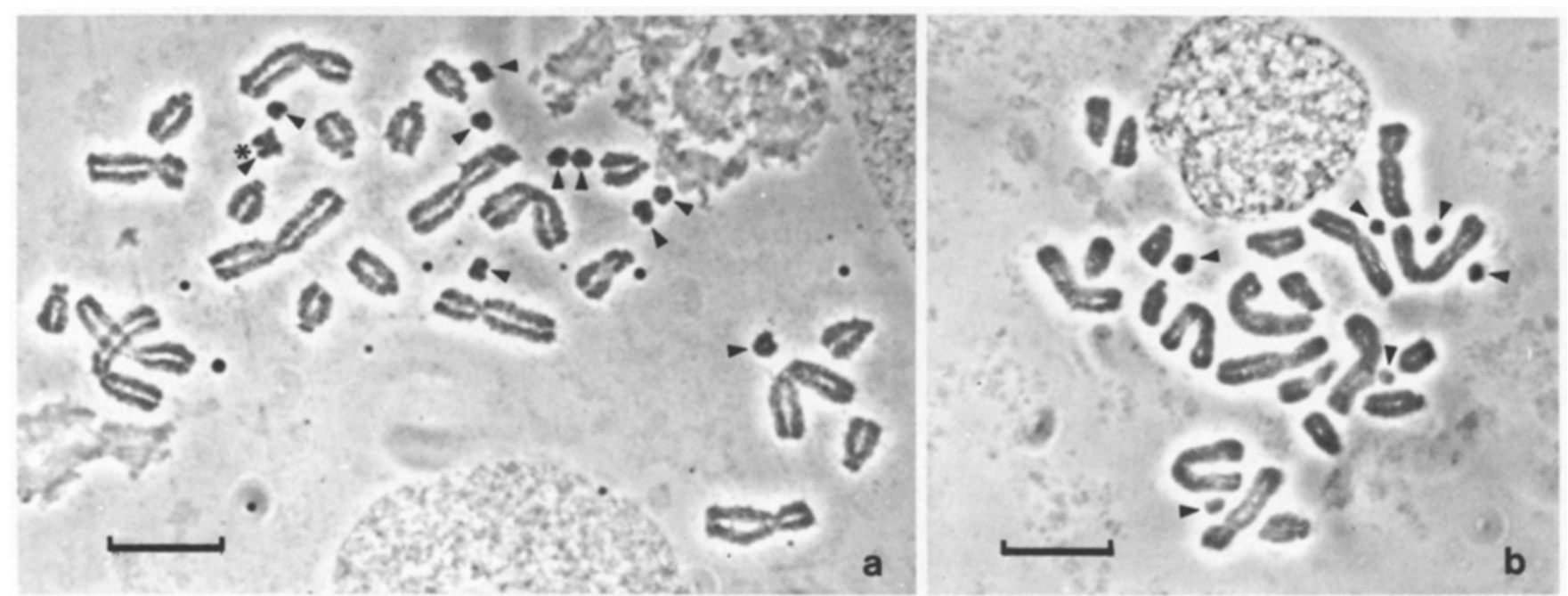

Fig. 2a, b. Unstained mitotic chromosome spreads obtained from corneal epithelium of Leiopelma hochstetteri from Tapu, New Zealand, viewed with phase contrast. Supernumerary chromosomes (arrows) are clearly visible. a Male with ten supernumerary chromosomes, one of which is metacentric (asterisk); b femalc with six supernumeraries. Note that supernumerary chromosomes can be of different sizes. Bars represent $10 \mu \mathrm{m}$ 
$0.87 \%$ of the A-set. The supernumerary chromosomes seen in females from I)ome Valley examined by Green el al. (1984a) wore measured at about $0.98 \%$ of the A-set. The metacentric supcrnumerary observed in one male from Tapu was among the largest of the supernumerarics obscrved; each of its two arms was smaller (about $0.72 \%$ of the A-set) than the smallest telocentric supernumerary.

The possibility of mitotic instability in inheritance of onc or more of the B-chromosomes was investigated by counting the numbers of supernumeraries in many different chromosome spreads of the same individual. In one male, 23 cells were examined. Of these, equal numbers of cells were observed to have 5 supernumeraries visible as were observed to have 6 supernumerarics ( 6 being the maximum number in this individual). Five of the 23 cells were observed to have fewer than 5 supernumeraries visible. In the male with 10 supernumeraries, many cells were observed where only 9 such chromosomes could be counted. However, the modal number of supernumeraries per cell was the same as the maximum number of supernumcraries per cell in every individual, indicating that the observed variation in number was probably artifactual.

C-banding revealed the presence of strongly staining heterochromatic regions at the centromeres of all the telocentric chromosomes and the supcrnumeraries of the lapu specimens. However. the centromeres of the large metacentric chromosomes of these individuals stained only weakly, or not al all (Fig. 3a, b). By contrast, results obtained from C-banding of chromosomes from Dome Valley frogs (Green et al. 1984a) showed that all their chromosomes, including the metacentrics, stained darkly at the centromeres. Only one of the metacentric chromosomes of the Tapu frogs, chromosome 3 , revealed dense C-band heterochromatin at its centromere. This band staincd much less strongly than did bands on the telocentrics and supernuineraries.

C-bands in addition to those associated with the centromeres of the chromosomes were noted in the Tapu frogs. The seventh chromosome had a prominent C-band associated with its secondary constriction (Fig. 3 a, b), as was observed in Dome Valley frogs (Green et al. 1984a). In the male with six supernumeraries, however, this band appeared to be heteromorphic in that one of the pair of scventh chromosomes had a much more intensely stained band than the other (Fig. 3 a). This frog also leatured numcrous weak C-bands on the "shoulders" of the long arms of the tclocentric chromosomes, proximal to the centromercs. The male with nine supernumeraries did not have the heteromorphism in C-banding on chromosome 7.

C-banding of the supernumerary chromosomes of the Tapu frogs was as observed before in Dome Valley specimens (Green el al. 1984a). Only the centromeres were heterochromalic (lig. 3a, b). The one small melacentric supernumerary observed in one of the males likewise stained only at its centromere.

Meiotic chromosome preparations were obtained from the spermatocyles of one of the Tapu males. Meiosis in this frog, which had nine supernumeraries and had becn inoculated with colchicine, was highly abnormal (Fig. 4 a, b). In some spreads, only the metacentric chromosomes appeared to be paired. Five large bivalents were observed among numerous small univalent elements (Fig. 4a). One of the melacentric pairs formed a conspicuous ring bivalent, indicating the presence of two terminal, or ncar-terminal,

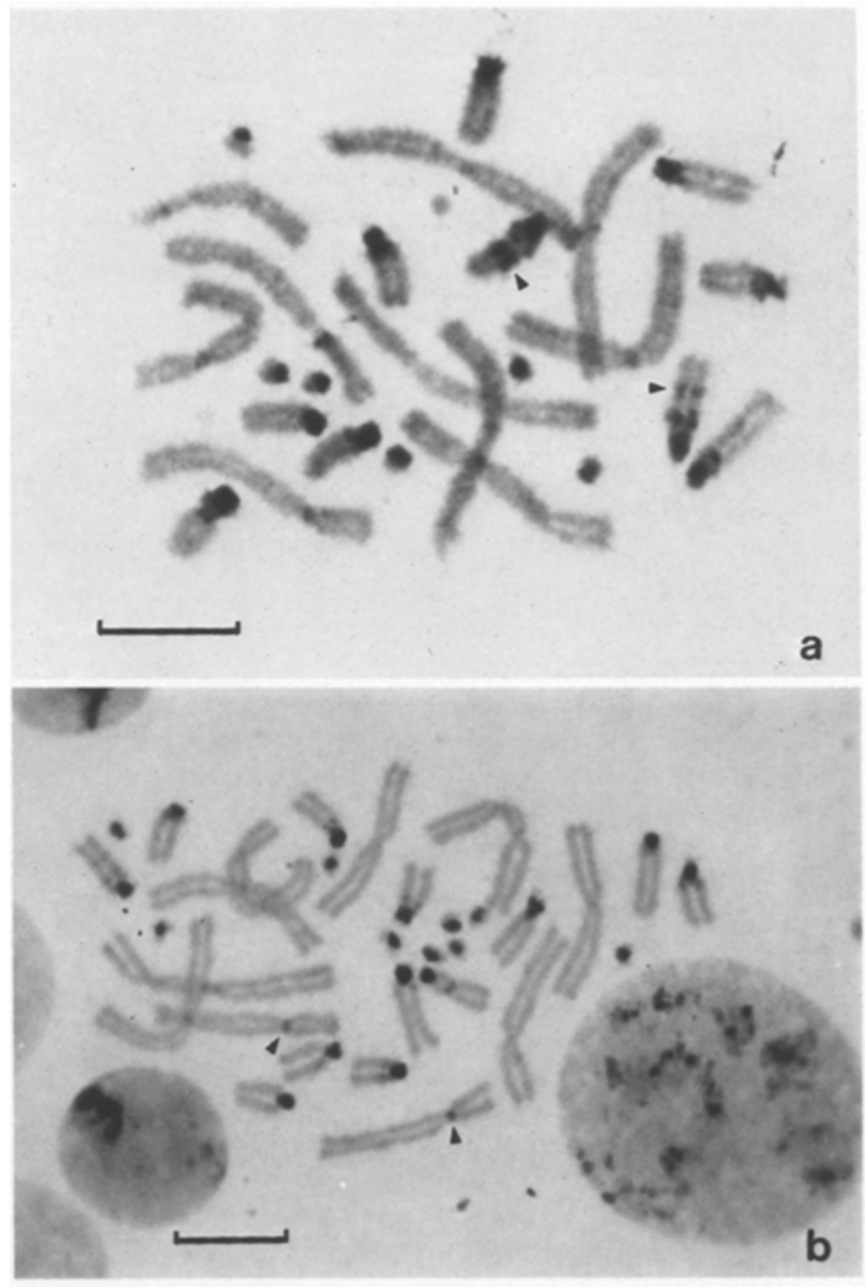

Fig. 3a, b. C-banded metaphase chromosone preparations from gut epithelium of Leiopelma hochstetteri from Tapu. New 7.caland, illustratc differential intensity of staining of centromeric heterochromatin between metacentric and felocentric chromosomes. a Male with six supernumerary chromosomes. Interstitial C-bands associated with the secondary constriction on chromosone 7 (arrows) are heteromorphic. b Male with nine supernumeraries. Only one metacentric chromosome pair, 3, has appreciable centromeric helcrochromatin (arrows). Bars represent $10 \mu \mathrm{m}$

chiasmata. All other bivalents had a single, terminal chiasma. A ring bivalent was not observed in meiotic preparations of $L$. hochstetteri as illustrated by Stephenson et al. (1972). Similar ring bivalents, though, are frequently observed in meiotic preparations from more "advanced" frogs such as Bufo or Rana (Morescalchi 1973). In other mciotic spreads from the same frog, however, differing numbers of telocentric A-chromosomes appeared to be paired. A C-banded preparation (Fig. 5) shows all of the metacentrics to be paired while some of the telocentrics are paired. bul not others. In another figure, all of the A-set chromosomes were paired. The supernumerary chromosomes always appeared as univalents.

l.ampbrush chromosomes were prepared from oöcyles of two females from Dome Valley. Since these individuals had not been treated with colchicine, we had not becn able to secure mitotic chromosomes from them. As in other females from this locality that we had examined earlier (Green et al. 1984a), cach of these two frogs had one super- 

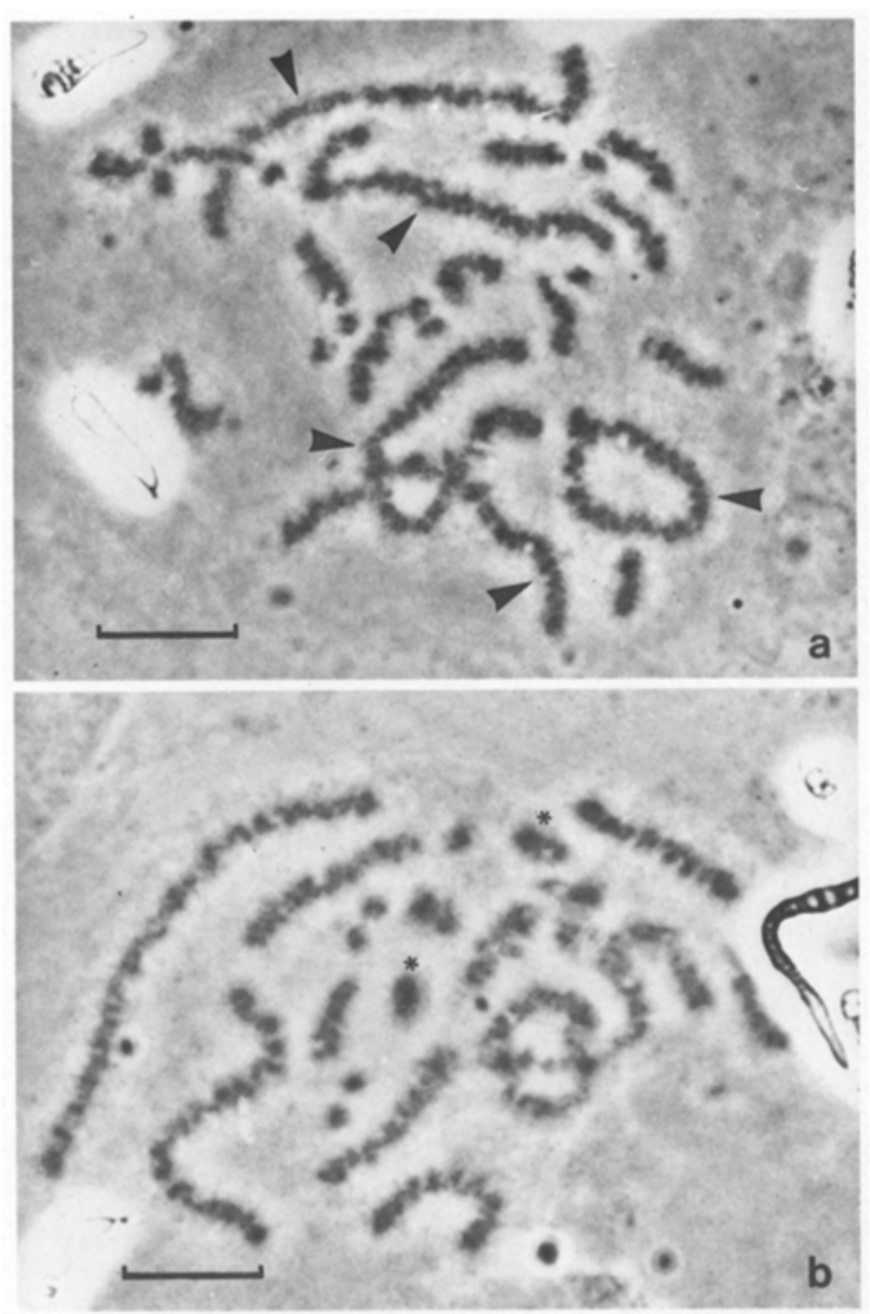

Fig. 4 a, b. Meiotic chromosomes al prometaphase from the colchicine-treated testis of a male Leiopelma hochstetteri with nine supernumerarics. a Only the live pairs of metacentric chromosomes (arrois) appear as bivalents, one as a ring bivalent. The six pairs of telocentric chromosomes are unpaired, as are the small supcrnumerarics. $\mathbf{b} A \mathrm{ll}$ chromosomes are paired except the supernumerarics and one pair of telocentrics (astcrisks). Bars represent $10 \mu \mathrm{m}$

numcrary chromosome per cell, clearly discernible in the lampbrush preparations (Fig. 6a, b). While the A-set lampbrush chromosomes werc paired as normal meiotic bivalents, displaying chiasmata and lateral loops, the supernumerary chromosome appeared as a more condensed univalent, with a dense, beaded axis and relatively few lateral loops (Fig. 6a, b).

\section{Discussion}

As of this study, 9 different cytolypes are known from 18 specimens of $L$. hochstetteri. Diploid karyotypes with $0,1,2,4,6,9,10$ and 12 supernumerarics have been found. Despite the small samples studied, there is an indication that the average number of supernumerary chromosomes per individual differs between populations (Table 1). $\Lambda$ verage supernumerary number appcars to increase with increasing latitude from Dome Valley to populations at Tokatea and Tapu along the Coromandel Peninsula (Fig. 1). One observation is at odds with this pattern: a 12 supernumer-

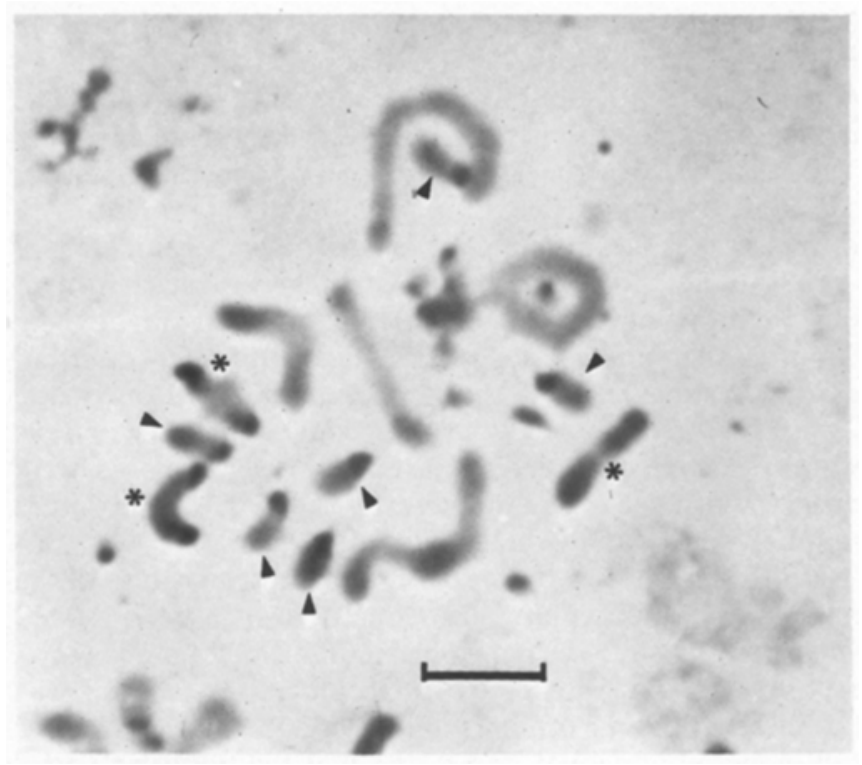

Fig. 5. C-banded meiolic preparation from the testis of the same specimen as in Figure 4 showing paired (asterisks) and unpaired (arrows) telocentric chromosomes. Bar represents $10 \mu \mathrm{m}$

ary chromosome karyolype found by Morescalchi (1967) in a frog reported to be from Dome Valley. l'urther investigations will reveal if a geographic trend is real and whether it may continue to outlying parts of the species' range.

While it has been suggested that supcrnumerary chromosomes are usually transcriptionally inactive (Jones and Rees 1982), visual cvidence from lampbrush chromosomes has been lacking. Our results indicate that the supernumerary chromosome in the lampbrush statc (Fig. 6a, b) does have short lateral loops indicative of transcriptional activity, though at a lower level than the A-chromosomes.

The variation in the staining intensity of centromeric helcrochromatin in the large metacentric chromosomes of L. hochstetteri is unusual. Variation in C-band staining has been seen in association with heteromorphic nucleolar organizer regions (NORs) in various frogs (King 1980; Schmid 1983). In one of the spccimens of $L$. hochstetteri from Tapu, a C-band hetcromorphism can be seen in the NOR-bearing chromosome 7 (I.ig. 3 a). IIowever, the striking variation observed in $I$.. hochstetteri involves only the metacentric chromosomes in apparent correlation with supernumerary chromosome number and/or with geographic distribution. The Dome Valley frogs had strongly C-band positive centromeric regions on all chromosomes while the Tapu frogs had litle or no C-banding at the centromeres of the metacentrics.

Variation in heterochromatin banding has been extensively studied in many rodents. Subspecies of the housc mouse, Mus musculus, have differing amounts of heterochromatin in certain chromosomes (Dev et al. 1976). $\Lambda$ similar sort of variation occurs in subspecies of the rat, Rattus rattus (Yosida and Sagai 1975). Patton (1977) found evidence of three types of supcrnumerary chromosomes in the pocket mouse, Perognathus baileyi, and slight associated variation in C-banding in the chromosomes of the A-set. Patton, however, did not see any correlation between helerochromatin variation and supernumerary number. The supernumerarics of $P$. baileyi include both totally heterochromatic and, rarely, partially heterochromatic types. 


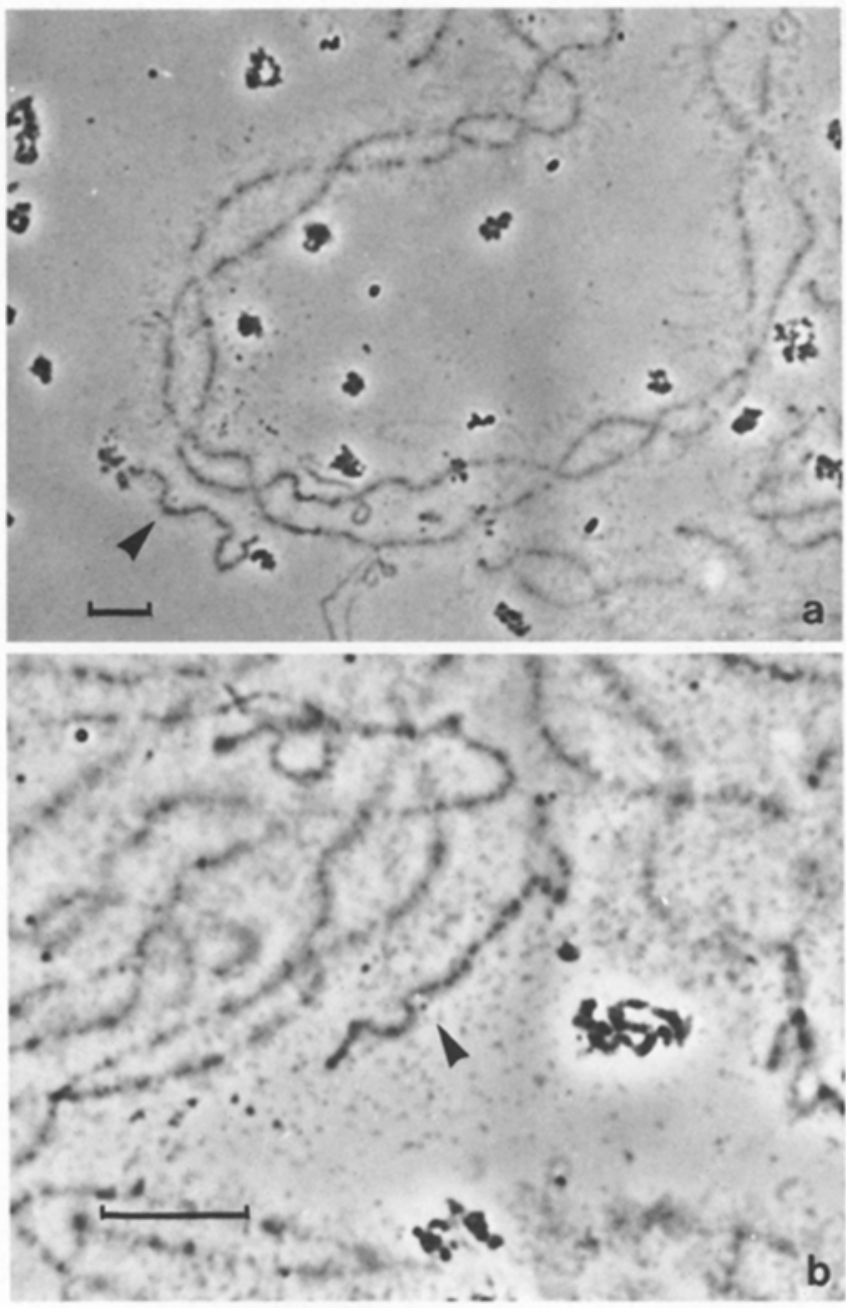

Fig. 6a, b. Lampbrush chromosomes from oöcyles of a female Leiopelma hochstetteri with one supernumerary chromosome (arrous). a Size and configuration of lampbrush supernumerary relative to a metacentric A-chromosone bivalent in lampbrush condition. b $A$ lampbrush supcrnumerary shoning its relatively dense, beaded condition with lew loops. Bars represent $10 \mu \mathrm{m}$

Among other amphibians, differences in amount of eentromeric heterochromatin have becn noted in chromosomes of other species, particularly subspecies of the red-legged Frog. Rana curora (Green 1985), and of the crested newt, Triturus cristatus (Sessions 1984). In these species, all chromosomes were affected and no supernumerary chromosomes were present although the additional heterochromalin differs markedly in its precise location in $R$. aurora and T. cristatus.

An example perhaps more like that seen in $I$. hochstetteri with regard to heterochromatin and supernumerary chromosomes was studied in the Australian rodent Uromy's caudimaculatus (Baverstock et al. 1976). Animals from two disjunct parts of this species' range had great differences in heterochromatin and supernumeraries. Northern animals had many C-band positive regions in the A-set, mostly as telomeric or interstitial bands, and had no supcrnumeraries. Southern animals had few heterochromatic regions in the A-set yet had six 10 nine totally heterochromatic supernumerary chromosomes. Unlike the chromosomes of L. hochstetteri, however, the centromeres of the A-chromosomes
Table 1. Numbers of supernumerary chromosomes known to be found in karyotypes of Leiopelna hochstelleri with the numbers of individuals, separated by sex, that have been found to possess those cytotypes

\begin{tabular}{|c|c|c|}
\hline \multirow{2}{*}{$\begin{array}{l}\text { Number of } \\
\text { supernumerary } \\
\text { chromosomes } \\
\text { per karyotype }\end{array}$} & \multicolumn{2}{|c|}{ Number of individuals and population } \\
\hline & Males & Fenales \\
\hline 0 & 2. Lome Valley ${ }^{\text {b.c }}$ & \\
\hline 1 & & 7, Dome Valley ${ }^{\text {a-d }}$ \\
\hline 2 & 2, Tokaleab & 1. Dome Valley" (triploid) \\
\hline 4 & 1, Tokalea ${ }^{b}$ & \\
\hline 6 & 1. Japu ${ }^{\mathrm{d}}$ & 1, Tapu ${ }^{d}$ \\
\hline 9 & 1. Tapu & \\
\hline 10 & 1. Tapu ${ }^{\mathrm{d}}$ & \\
\hline 12 & & 1, 1)ome Valley: \\
\hline
\end{tabular}

Data computed from all know sources

"Morescalchi (1967)

b Stephenson et al. (1972)

" Green el al. (1985)

$\checkmark$ Present study

of $U$. caudimaculatus were relatively unaffected, and the supcrnumcraries had no cuchromatic regions.

The pattern of heterochromatin variation in $L$. hochstetteri is interesting in that only centromeric heterochromatin seems to be involved and only certain morphologically distinct chromosomes secm to be affected. The presence of increasing numers of supernumerary chromosomes appears to relate to meiotic behaviour of the A-set as well. It has been argued that in certain plants, for instance, supernumerary chromosomes can affect pairing of the $\Lambda$-set in meiosis. Parker et al. (1981) suggested that supernumerary chromosomes affect chiasma frequency in the A-set in $\mathrm{Hy}_{\mathrm{y}}$ pochoeris maculata (Family Compositae) and produce other effects which disrupt normal mciosis when the number of supernumeraries exceeds one. Patton (1977) also found effects on meiotic chiasma formation among the A-chromosomes in the presence of supernumeraries in the pocket mouse $P$. baile $i$. Limited evidence from the present investigations of the karyology of $I$. hochstetteri seems to indicate that supernumeraries may inlluence synapsis of bivalents in meiosis in L. hochstetteri. A single male without supernumeraries from Dome Valley from whom meiotic chromosome preparations were made by Stephenson el al. (1972) showed no deviations from normally expected pairing of all normal chromosome homologs. However, our results from a malc frog from Tapu with nine supcrnumeraries showed a case in which different elements exhibited varying degrees of asynapsis or chiasma failure. One pair of large metacentrics also formed a circular bivalent with terminal chiasmata. The individual we examined may have been abcrant but the colchicine used is unlikely to have been responsible for the effects upon meiosis that we observed.

The origins of supernumerary chromosomes are as yet nithout clear explanation. Two phenomena must he considered in this context : the origination of supernumeraries and the accumulation of pre-existing supernumeraries. Certainly supernumeraries have accumulated in certain, but not all, populations of $I$. hochstenteri. Among Dome Valley specimens. supernumeraries were found only in females (lable 1). Meiotic accumulation mechanisms have been pro- 
posed, pertaining in particular to certain plants (Jones and Rees 1982). Progressive origination of supernumeraries cannot be ruled out in $L$. hochstetteri, however. The different sizes of supernumerarics indicate that they are not all identical and thus probably do not represent proliferation of a single chromosome. The metacentric supernumerary chromosome found in one malc has no counterpart in other individuals examined. It may have arisen separately, or be the product of fusion of two very small tclocentric supernumeraries, or be an iso-chromosome.

It is possible that at least some of the supernumeraries in the Tapu frogs may have arisen as centromeric fragments, especially as fragments from the large metacentrics. This sort of mechanism has been discussed by Pation (1977) and Jones and Rees (1982). The loss of centromeric fragments preferentially from the large metacentrics, with their accompanying heterochromatin, is an explanation consistent for both the possible origination of the supernumerary chromosomes of $L$. hochstetteri and the observed patterns of heterochromatin distribution seen in this species. However, the apparent increase in functional kinctochores represented by the supernumerary chromosomes awaits explanation.

We have made a number of assertions concerning the distribution, effect and origin of the supernumerary chromosomes of $L$. hochstetteri based on the information at hand. Obviously, however, the volume of that information is limited by the relatively small number of specimens availablc of this rare frog. Our hypotheses concerning apparen geographical differentiation in numbers of supernumerary chromosomes present per individual could be proven false if additional animals with other numbers of supernumeraries are found: higher numbers from Dome Valley and lower numbers from Tapu, for example. This would also provide information on the possible occurrence of karyotypes with very high numbers of supernumerary chromosomes, such as described by Morescalchi (1967). If these other karyotypes are present, the apparent correlation of supernumeraries with heterochromatin distribution could be tested. Is the observed variation related to geographic divergence or to gain of supernumerarics? At present, these cannot be separated. Other populations of L. hochstetteri, on Great Barrier Island or in the East Cape region, for example, have not been examined karyotypically. The lampbrush behavior of the supcrnumerary chromosomes were more than one is present is also unknown. We hope that further studies may be possible to address these questions.

Acknowledgements. We arc grateful to Dr. Joan Robb for providing the specimens uscd in this study and to Dr. R.C. Drewes for making available two of those sent to the California Academy of Sciences. Dr. W.F. Grant kindly provided use of his computer and Drs. S.K. Sessions and C.II. Daugherly offered valuable comments upon the manuscript. This study was supported in part by NSFRC Canada grants A2198 and U()-526 to DMG.

\section{References}

Baverstock PR, Watts CHS, Hogarth JT (1976) I Ieterochromatin variation in the Australian rodent Uromys caudimaculatus. Chromosoma 57:397-403

Bell 131) (1982) The amphibian fauna of New Zealand. In: New'man DG (ed) New Zcaland herpetology. New Zealand Wildlife Service, Wellington, pp 2789

Bell BD (1986) 'The conservation status of New Zealand wildlife. Occ Publ N-Z Wildlife Serv $12: 1-103$
Bogart JP (1981) Chromosonc studics in Sminthillus from Cuba and I:leutherodactylus from Cuba and Puerto Rico (Anura, Lcplodactylidae). Life Sci Contrib $R$ Ontario Muscum 129:1-22

Dev VG, Miller DA, I'antravani RR, Schreck RR, Roderick TH, Erlanger BF, Miller OJ (1976) Chromosome markers in Mus musculus: differences in C-banding between the subspecics $M$. m. musculus and M. m. molossinus. Chromosoma 53:335 344

Duellman WE, Trueb I. (1986) The biology of amphibians. McGraw-Hill Book Co. Ncw York, p 670

Green DM (1985) Differentiation in amount of centromeric heterochromatin between subspecies of the red-legged frog, Rana aurora. Copcia 1985:1071-1074

Green DM, Bogart JP, Anthony EH, Genner DL (1980) An interactive, microcomputer based karyotype analysis system for phylogenetic cytotaxonomy. Comput Biol Mcd 10:219-227

Green DM, Kezer J, Nussbaum RA (1984a) Triploidy in Hochstetter's frog Lciopelma hochstetteri from New 7caland. N7. J Zool 11:457-461

Green DM, Myers P'Z, Reyna DL (1984b) CHROMPAC III: an improved package for micro-computer assisted analysis of karyolypes. J Hered 75:143

I Iarvey $\Lambda \mathrm{W}$, Hewill GM (1979) B-chromosomes slow development in a grasshopper. Heredity 42:397 401

Jones RN, Rees 11 (1982) B-Chromosomes. Academic Press, New York, p 266

Kezer J, Sessions SK (1979) Chromosome variation in the plethodontid salamander Aneides ferreus. Chromosoma 71:65 80

Kezer J, Léon PE, Sessions SK (1980) Structural diffcrentiation of the meiotic and mitolic chromosomes of the salamander Ambystoma macrodactylum. Chromosoma 81:177 197

King M (1980) C-banding studies on Australian hylid frogs: Sccondary constriction structure and the concept of euchromatin transformation. Chromosoma 80:191-217

Levan $\Lambda$. Fredga $D$, Sandberg $\wedge \wedge$ (1964) Nomenclature for centromeric position on chromosomes. Hereditas 52:201-220

Morescalchi $A$ (1967) The karyolype of two specimens of Leiopelma hochsicticri Fitz. (Amphibia Salientia). Caryologia $21: 37-46$

Morescalchi A (1973) Amphibia. In: Chiarclli $\Lambda$, Capanna $E$ (eds) Cytotaxonomy and vertebrate cvolution. Academic Press, New York, pp 233-283

Patton JL (1977) B-chromosome systems in the pocket mouse, Perognathus bailcyi: Mciosis and C-band studies. Chromosoma $60: 1-14$

Parker JS, Ainsworth CC, Taylor S (1981) The B-chromosome system of Hypochocris maculata II. B-effects on mciotic Achromosome behaviour. Chromosoma 67:123-143

Schmid M (1978) Chromosome banding in amphibia I. Constitutive hetcrochromatin and nuclcolus organizer regions in Bufo and Tyla. Chromosoma 66:361-388

Schmid M (1983) Chromosome banding in Amphibia. VIl. Analysis of the structure and variability of NORs in Anura. Chromosoma $87: 327-344$

Sessions SK (1984) Cylogenetics and evolution in salamanders. $\mathrm{Ph}$.D. dissertation. University of California, Berkeley

Stephenson EM, Robinson ES, Stephenson NG (1972) Karyotype variation wilhin the genus Leiopclma (Amphibia: Anura). Can J Genet Cytol 14:691-702

Stephenson EM, Robinson ES. Stephenson NG (1974) Inter-specilic relationships of Lciopelma (Amphibia: Anura). Further karyological evidence: Experientia 30:1248-1250

Yosida TII, Sagai T (1975) Variation of C-bands in the chromosomes of several subspecies of Ratlus ratlus. Chromosoma $50: 283-300$

Received liebruary 18, 1987 : in revised form May 19, 1987 Accopted by $\mathrm{H}$. Macgregor 